\title{
Mental health and quality of life in patients with cervical dystonia
}

\section{Tomoyuki Kawada ${ }^{1}$}

Received: 28 November 2019 / Accepted: 13 April 2020 / Published online: 22 April 2020

(C) Fondazione Società Italiana di Neurologia 2020

Dear Editor,

I have read the article entitled as "Evaluation of anxiety and depression scales and quality of LIFE in cervical dystonia patients on botulinum toxin therapy and their relatives" by Ceylan et al. with interest [1]. The authors investigated quality of life and psychiatric comorbid disorders in 30 patients with cervical dystonia and their spouses. The authors also investigated the effect of botulinum toxin (BTX) treatment on health-related outcomes. Depression and anxiety were more frequently observed and the quality of life became poor in patients. In spouse, depression and anxiety were also increased, but vitality, mental health, and general health perception were kept good. The authors also recognized that patients showed improvements in anxiety level, disease activity, and overall quality of life scales after BTX treatment. There are papers that psychosocial factors might affect quality of life in patients with cervical dystonia $[2,3]$. I have a concern with this study.

Treatment effects of BTX for cervical dystonia patients have been evaluated mainly on subjective symptoms and objective findings. Recently, Colosimo et al. reported a prospective study concerning the effect of botulinum neurotoxin type A (BoNT-A) over 3 years in patients with cervical dystonia patients [4]. Despite objective clinical improvements over 3 years, patient satisfaction with symptom control remained constant. They speculated that other than symptom control contributed to patient satisfaction. I suppose that Ceylan et al. might speculate interrelationship among physiopsychosocial factors in patients, and subject satisfaction would be closely related to anxiety, depression, and quality of life.

Tomoyuki Kawada

kawada@nms.ac.jp

1 Department of Hygiene and Public Health, Nippon Medical School, 1-1-5 Sendagi, Bunkyo-Ku, Tokyo 113-8602, Japan
Relating to a query, Werle et al. reported the functional, clinical, and quality of life profiles in 70 patients with cervical dystonia [5]. The greater the disability, pain, and severity of dystonia presented, quality of life became worse. The physical and psychosocial factors contributed to the quality of life in patients with cervical dystonia $[2,3]$, and interventional studies concerning the effect of botulinum toxin therapy on subsequent multidimensional health outcomes should be conducted.

\section{Compliance with ethical standards}

Conflict of interest The author declares that he has no conflict of interest.

Ethical approval None.

\section{References}

1. Ceylan D, Erer S, Zarifoğlu M, Türkeș N, Özkaya G (2019) Evaluation of anxiety and depression scales and quality of LIFE in cervical dystonia patients on botulinum toxin therapy and their relatives. Neurol Sci 40:725-731

2. Tomic S, Petkovic I, Pucic T, Resan B, Juric S, Rotim T (2016) Cervical dystonia and quality of life. Acta Neurol Belg 116:589-592

3. Ben-Shlomo Y, Camfield L, Warner T, ESDE collaborative group (2002) What are the determinants of quality of life in people with cervical dystonia? J Neurol Neurosurg Psychiatry 72:608-614

4. Colosimo C, Charles D, Misra VP, Maisonobe P, Om S, INTEREST IN CD2 study group (2019) How satisfied are cervical dystonia patients after 3 years of botulinum toxin type a treatment? Results from a prospective, long-term observational study. J Neurol 266: 3038-3046

5. Werle RW, Takeda SY, Zonta MB, Guimarães AT, Teive HA (2014) The physical, social and emotional aspects are the most affected in the quality of life of the patients with cervical dystonia. Arq Neuropsiquiatr 72:405-410

Publisher's note Springer Nature remains neutral with regard to jurisdictional claims in published maps and institutional affiliations. 